\title{
Wideband and Compact Wilkinson Power Divider Utilizing Series Delta-Stub and Folded Stepped-Impedance Transmission Line
}

\author{
Nadera AL-AREQI, Kok Yeow YOU, Chia Yew LEE, \\ Nor Hisham KHAMIS, Mohamad Ngasri DIMON
${ }^{1}$ Dept. of Communication Engineering, Faculty of Electrical Engineering, Universiti Teknologi Malaysia, 81310 Skudai, Johor, Malaysia

nadera.areqi@fkegraduate.utm.my, kyyou@fke.utm.my, chiayew1@gmail.com, hisham@utm.my, ngasri@utm.my

Submitted March 7, 2017 / Accepted December 6, 2017

\begin{abstract}
In this paper, a Wilkinson power divider is modified using four-series delta-stub and folded steppedimpedance transmission line (FSITL) in order to achieve a reduced circuit size of $84 \%$ and fractional bandwidth of $116 \%$. Series delta-stubs are used instead of open shunt stubs to obtain an optimum shifting frequency and wider bandwidth. Folded stepped-impedance transmission line (FSITL) is used to achieve reduced circuit size. The proposed power divider is fabricated using RT/duroid 5880 substrate with thickness of $0.38 \mathrm{~mm}$. The dimension of the power divider is $13 \mathrm{~mm} \times 6.5 \mathrm{~mm}$. The proposed power divider has typical power division of $-3 \mathrm{~dB}$ and insertion loss less than $-1 d B$, better than $-13 d B$ of isolation, less than $-10 \mathrm{~dB}$ return loss and phase imbalances less than $2^{\circ}$ from 1.5 to $3 \mathrm{GHz}$. Both simulation and measurement results show a good agreement.
\end{abstract}

\section{Keywords}

Wilkinson power divider, wideband, compact size, series delta-stub, folded stepped-impedance, $S$-parameters

\section{Introduction}

Conventional Wilkinson power dividers (WPD) [1] are usually used for power division in microwave communication systems since they have a good isolation between the two separated output ports, a low insertion loss, and a simple fabrication process. However, these power dividers have large circuit size due to the application of long transmission line ( $\lambda / 4$ length) to match the output port to the input port, particularly for lower operating frequencies RF systems. In addition, the conventional circuit has a narrow bandwidth.

Recently, the design of WPD has adopted many techniques [2-12] to miniaturize the circuit size of the power divider, nevertheless, these techniques suffered serious degradation of the return-loss bandwidth compared with the conventional structure. For instance, in [9], the WPD was proposed using two-section asymmetrical $T$-structures to achieve a significant size reduction. The asymmetrical $T$-structures were represented by two series of high-impedance lines but the phase delay was not $90^{\circ}$. Due to this reason, the isolation circuit should consist of not only resistance but also capacitance/inductance [23]. Step impedance transmission lines (SITL) was used to reduce the size of microstrip components as in [7], [8], [10]. In [7], they proposed a new idea based on SITL to compact the quarter wave length transmission lines in the WPD. According to [11], [12], folding stepped-impedance transmission line (FSITL) can provide a more compact circuit size. Even though, these approaches can provide up to $60-80 \%$ circuit size reductions, they have limited bandwidths.

Recent efforts [13], [14] have shown that the Wilkinson's design can be modified to achieve a wider bandwidth. Multilayer PCB technology was used by [13], to enhance the operating bandwidth of the power divider. Some researchers [15] enhanced the bandwidth of the power divider via coupled microstrip lines and shunt open-ended stubs resulting in a good power splitting performance. On the other hand, it increases the size and the complexity of circuit fabrication. De Lima Coimbra [16], [17] was the first to propose the single delta-stub which provides wider bandwidth. In [18], they incorporated delta-stub in both WPD arms to achieve ultra-wide band (UWB) characteristics; however they did not reduce the size although high center frequency of $6.85 \mathrm{GHz}$ was used. All these proposed techniques may increase the circuit size and insertion loss [10].

Some of the methods also make the structure complex, costly to manufacture and incompatible with microstrip circuits [20], [21]. In this study, a series delta-stubs (SDS) is implemented to shift the high operating frequency to low frequency while maintaining short branch lines. In addition, by adjusting the dimensions of the delta-stub, the 
operating bandwidth can be widened. The quarter-wave line section was replaced by folded stepped-impedance transmission line (FSITL). The series stub, which is a combination of four-series delta-stub, is applied in each branch to achieve a more compact size and wideband. In this work, wideband and compact Wilkinson power divider of center frequency $2.4 \mathrm{GHz}$ was developed.

\section{Proposed Design}

The designed Wilkinson power divider is shown in Fig. 1 for a desired center frequency of $2.4 \mathrm{GHz}$. Two parts of the modified power divider are going to be discussed separately: series delta-stub (SDS) and folded steppedimpedance transmission line (FSITL).

The SDS is modified based on a single delta openstub shown in Fig. 2. By considering the single delta-stub, it can be divided into $n$ discrete segments of microstrip transmission line of length $\delta$. The length $\delta$ should obey the condition $\delta<<\lambda_{g}$, where $\lambda_{g}$ is the electrical wavelength. The narrow width segment of the stub which has higher characteristic impedance is merged with the microstrip transmission line of the power divider. The last widest segment of the stub with low impedance plays a role as an open ended discontinuity as shown in Fig. 2(b). The analytical design procedures of the delta-stub are demonstrated by several steps:

\section{Step 1:}

First, the desired size of the designed power divider circuit is fixed to be $(13 \times 6.5) \mathrm{mm}^{2}$. However, the smaller size of the power divider circuit was given $3.2 \mathrm{GHz}$ of the operating center frequency, $f_{\mathrm{c}}$, which is higher than expected center frequency, $f_{\mathrm{c}}{ }^{\prime}=2.4 \mathrm{GHz}$. Here, the modification of the pre-designed circuit was done in order to shift $f_{\mathrm{c}}$ from $3.2 \mathrm{GHz}$ to $2.4 \mathrm{GHz}$ without increasing the physical transmission length.

The empirical equations (1) to (5) were obtained by polynomial regression fitting based on the CST simulation data. Up to 15 fitting coefficients $\left(a_{1}, \ldots, a_{5} ; b_{1}, \ldots, b_{5}\right.$; $\left.c_{1}, \ldots, c_{5}\right)$ are chosen to provide a greater degree of freedom for the regression fitting.

$$
f_{\mathrm{c}}^{\prime}=f_{\mathrm{c}}-\Delta f
$$

where the shifted frequency, $\Delta f$ is given as:

$$
\Delta f=\alpha \times n_{\text {series }}^{2}+\beta \times n_{\text {series }}+\gamma .
$$

Symbols $\alpha, \beta$ and $\gamma$ in (2) are expressed as:

$$
\begin{gathered}
\alpha=a_{1} \theta^{4}+a_{2} \theta^{3}+a_{3} \theta^{2}+a_{4} \theta+a_{5}, \\
\beta=b_{1} \theta^{4}+b_{2} \theta^{3}+b_{3} \theta^{2}+b_{4} \theta+b_{5}, \\
\gamma=c_{1} \theta^{4}+c_{2} \theta^{3}+c_{3} \theta^{2}+c_{4} \theta+c_{5}
\end{gathered}
$$

where $\theta$ (in degree) is the vertex angle of the delta-stub and $n_{\text {series }}$ is the number of delta-stub connected in series form

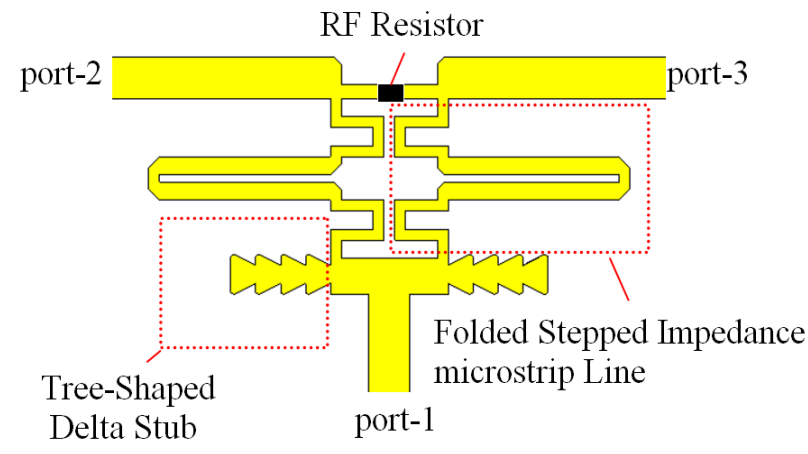

Fig. 1. The proposed design layout.

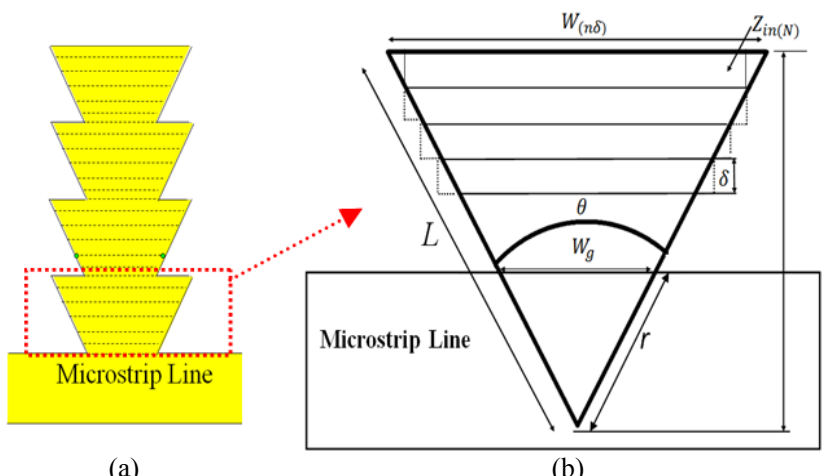

Fig. 2. (a) Four-series delta stubs and the (b) geometry of the delta stub [18].

as shown in Fig. 2(a). Symbols $a_{n}, b_{n}$, and $c_{n}(n=1,2, \ldots, 5)$ are the polynomial coefficients and their values are listed in Appendix (in Tab. A). First of all, the required shifting frequency, $\Delta f$ (in $\mathrm{GHz}$ ) from high to low needs to be determined. The number of series delta-stub, $n_{\text {series }}$ in each branch is chosen and it must be a positive integer $\geq 1$. Then, the angle, $\theta$ of the delta-stub is chosen within the range of $10^{\circ}<\theta<65^{\circ}$, and substituted into (3) to (5). Once the values of $\alpha, \beta$, and $\gamma$ are obtained, they are substituted along with $n_{\text {series }}$ into (2) to make sure that $\Delta f$ is the same as the determined shifting frequency. If $\Delta f$ is less than the determined shifting frequency, the value of $\theta$ or $n_{\text {series }}$ should be slightly increased and vice versa.

In this study, the reason behind choosing exactly four-series delta-stubs in each branch with $\theta=26^{\circ}$ is to meet the required performance parameters at $2.4 \mathrm{GHz}$, such as:

- Return loss, $\left|S_{11}\right|$ at input port $<-10 \mathrm{~dB}$.

- Return loss, $\left|S_{22}\right|,\left|S_{33}\right|$ at two output ports $<-10 \mathrm{~dB}$.

- Insertion loss, $\left|S_{21}\right|,\left|S_{31}\right|$ from input to output ports $\sim-3 \mathrm{~dB}$.

- Isolation, $\left|S_{32}\right|$ between the two output ports $<-20 \mathrm{~dB}$.

- Fractional bandwidth up to $110 \%$.

Figure 3(a) depicts the relationship between the number of delta-stubs, center frequency, $f_{\mathrm{c}}$ and angle, $\theta$. From Fig. 3(a), it can be noticed that the center frequency, $f_{\mathrm{c}}$ is shifted to a lower frequency, $f_{\mathrm{c}}{ }^{\prime}$ by increasing the number of delta-stubs, $n_{\text {series }}$ and the angle, $\theta$. It should be taken into account that adding more series of delta-stub improves 


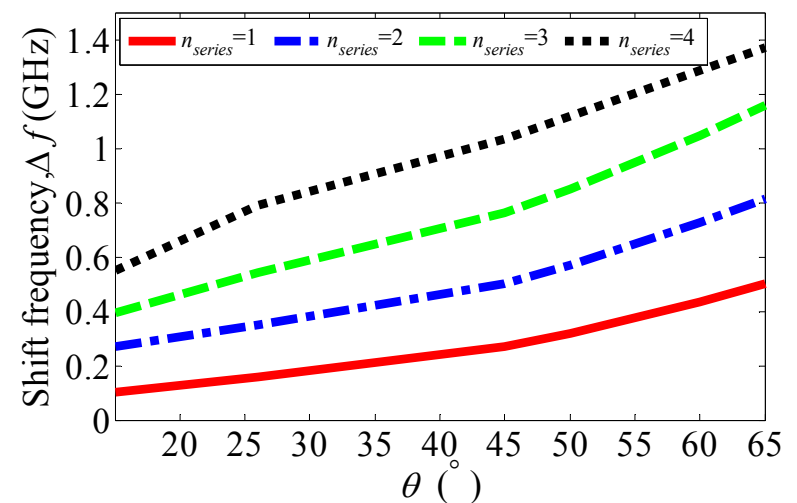

(a)

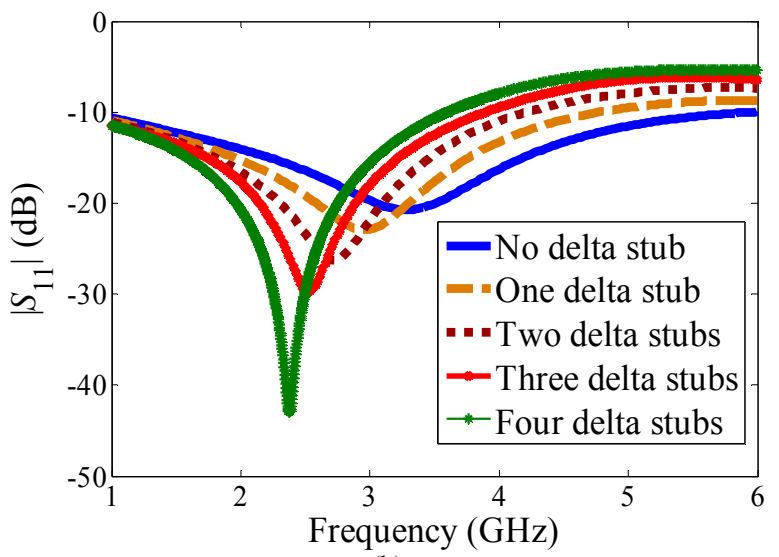

(b)

Fig. 3. (a) $2 \mathrm{D}$ plot, the relationship between number of series delta-stubs, angle and the resonant frequency, (b) 2D plot.

the return loss, $\left|S_{11}\right|$, on the other hand, that will influence the bandwidth as shown in Fig. 3(b).

\section{Step 2:}

Secondly, the transmission line widths, $W_{n \delta}$ of the segment are calculated by [18]

$$
W_{n \delta}=(2 n \delta) \cdot \tan (\theta / 2), \quad n=0,1, \ldots, N
$$

where subscript $n$ is the number of the segments in the delta-stub. It is worth to mention that $\theta=26^{\circ}$ was chosen based on studying different angles for four-series deltastubs in order to get the desired center frequency of 2.4 GHz as shown in Fig. 3(a).

The input impedance, $Z_{\text {in }(n)}$ of each $n$-segment is obtained by (7) with the exception of the final section $\left(Z_{\text {in }(N)}\right)$ since it has the open ended discontinuity. For $W_{n \delta} / h>1$, the $Z_{\text {in }(n)}$ of each $n$-segment is calculated as [1]:

$$
Z_{\mathrm{in}(n+1)}=Z_{\mathrm{in}(n)} \frac{Z_{\mathrm{o}(n)}+\mathrm{j} Z_{\mathrm{in}(n)} \tan (\beta \delta)}{Z_{\mathrm{in}(n)}+\mathrm{j} Z_{\mathrm{o}(n)} \tan (\beta \delta)}
$$

where the characteristic impedance, $Z_{\mathrm{o}(n)}$ of each $n$-segment is expressed as:

$$
Z_{\mathrm{o}(n)}=\frac{120 \pi}{\sqrt{\varepsilon_{\mathrm{e}}}\left\{\left(W_{n \delta} / h\right)+1.393+0.667 \ln \left[\left(W_{n \delta} / h\right)+1.444\right]\right\}}
$$

and the effective dielectric constant, $\varepsilon_{e}$ in (8) is given as:

$$
\varepsilon_{\mathrm{e}}=\frac{\varepsilon_{\mathrm{r}}+1}{2}+\frac{\varepsilon_{\mathrm{r}}-1}{2} \frac{1}{\sqrt{1+12 h / W_{n \delta}}} .
$$

The input impedance of the delta-stub can be found from the computation of the input impedance, $Z_{\text {in }(n)}$ of each cascaded transmission line with incremental distance $\delta$. According to (6) to (9), $n$ was chosen to be 42 to enable calculating the impedance of the delta-stub, $\mathrm{Z}_{\text {in(1) }}=57.94 \Omega$ and $Z_{\text {in }(N)}=83 \Omega$. The electrical parameters for the deltastub were computed as: $W_{\mathrm{g}}=0.5 \mathrm{~mm}, L=1.88 \mathrm{~mm}, r_{i}=$ $1.14 \mathrm{~mm}, \theta=26^{\circ}, W_{n \delta}=0.95 \mathrm{~mm}, \delta=0.048 \mathrm{~mm}, \varepsilon_{\mathrm{r}}=2.2$ and thickness, $h=0.38 \mathrm{~mm}$. When adding the four-series delta-stubs, the center frequency was successfully shifted to $2.4 \mathrm{GHz}$. This resulted in a size reduction of $44 \%$ compared to the conventional Wilkinson power divider at the same center frequency; however, fractional bandwidth (FBW) is reduced by $8 \%$. Therefore, in order to improve the reduction of bandwidth and get more size reduction, stepped-impedance transmission line is used [7], [8], [24], [28].

\section{Step 3:}

Figure 4 shows the second step in the design process which is to replace the uniform branch line with non-uniform SITLs while maintaining the impedances of input and output ports at $50 \Omega$. The stepped-impedance-stub lines design equations provide two degrees of freedom for circuit dimensions determination. These degrees of freedom can be used to reduce the circuit size [7].

The SITL possesses two different characteristic impedance lines and both appeared to be symmetrical. A stepped-impedance transmission line consisting of a low impedance line section and two identical high impedance line sections is depicted in Fig. 4. The low impedance line section $\left(Z_{1}\right.$ line $)$ is in the middle with electrical length $\theta_{1}$ and the two identical high impedance line sections with characteristic impedance $Z_{2}$, and electrical length, $\theta_{2} / 2$ are on both sides. The desired total electrical length, $\theta_{\mathrm{t}}=\theta_{1}+\theta_{2}$ is less than $45^{\circ}$ at center frequency of $2.4 \mathrm{GHz}$ [7]. The impedance ratio, $Z_{2} / Z_{1}=K$ of SITL can reduce the length when $K>1$ [7], [24]. The equations from (1) to (6) in

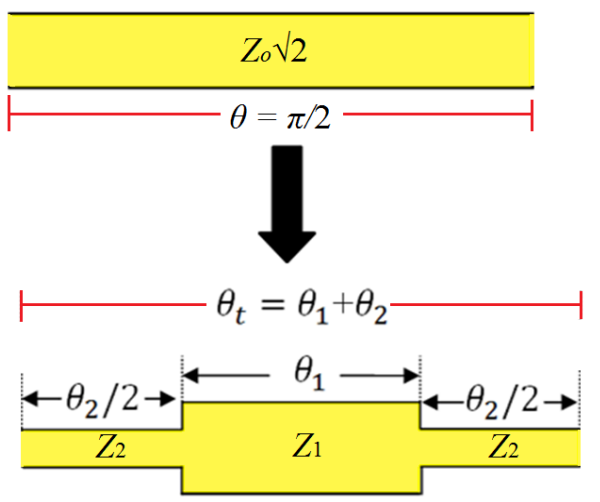

Fig. 4. Replacing the uniform transmission line with nonuniform SITLs transmission line [7]. 


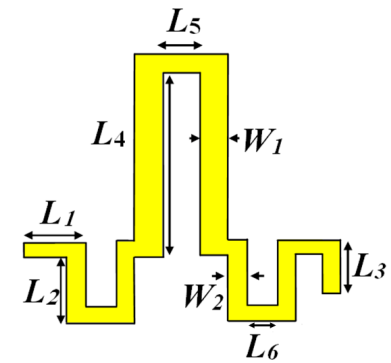

Fig. 5. Folded SITL transmission line.

\begin{tabular}{|c|c|c|c|}
\hline Parameters & Values & Parameters & Values \\
\hline$K$ & 1.25 & $L_{3}$ & $1.0 \mathrm{~mm}$ \\
\hline$Z_{1}$ & $81 \Omega$ & $L_{4}$ & $3.0 \mathrm{~mm}$ \\
\hline$Z_{2}$ & $102 \Omega$ & $L_{5}$ & $0.2 \mathrm{~mm}$ \\
\hline$\theta_{1}$ & $26.2^{\circ}$ & $L_{6} L_{7}$ & $0.5 \mathrm{~mm}$ \\
\hline$\theta_{2} / 2$ & $13.8^{\circ}$ & $W_{1}$ & $0.5 \mathrm{~mm}$ \\
\hline$L_{1}, L_{2}$ & $1.5 \mathrm{~mm}$ & $W_{2}$ & $0.3 \mathrm{~mm}$ \\
\hline
\end{tabular}

Tab. 1. Values of design parameters.

[7] are used to determine the optimum values of $Z_{2}, Z_{1}$ and $K$ when $\theta_{1}=\theta_{2}=\theta_{\mathrm{t}} / 2$.

Selecting a very high impedance ratio, $K$ is necessary to achieve compactness in the lines length; however, the limitations for achieving very high impedance lines $(W / h<<1)$ and very low impedance lines $(W / h>>1)$ should be taken into account. Furthermore, high impedance ratio, $K$ leads to high discontinuity effects. This means that high value of $Z_{2}$ is required, but this will result in a very narrow bandwidth. In addition, if $Z_{1}$ is extremely low, this will result in a wider microstrip line. Due to this reason, it will be difficult to fabricate. In this work, the desired total electrical length of the structure is $\theta_{\mathrm{t}}=\theta_{1}+\theta_{2}$ and $\theta_{\mathrm{t}}$ should be less than $40^{\circ}$ at center frequency of $2.4 \mathrm{GHz}$. By folding the stepped-impedance line [7], the total physical size was reduced by $84 \%$ as shown in Fig. 5 . The dimensions and parameters of FSITL are tabulated in Tab. 1.

\section{Results}

The proposed Wilkinson power divider is designed to operate for equal power division across the band $1 \mathrm{GHz}$ to $3.5 \mathrm{GHz}$. Figure 6 shows the actual circuit of the proposed power divider using four-SDS and FSITL structures. This modified power divider has $84 \%$ reduction size compared to the conventional power divider at the same center frequency of $2.4 \mathrm{GHz}$. The simulated and measured $S$-parameters results of the modified power divider are presented in Figs. 7 and 8(a), respectively. In spite of the fact that the simulation and measurement results show significant agreement, there is a minor difference due to the tolerance in fabrications. The measurements were taken by using an Agilent E5071C network analyzer.

The imbalance between insertion loss $\left|S_{21}\right|$ and $\left|S_{31}\right|$ is less than $\pm 2 \mathrm{~dB}$ from $1.5 \mathrm{GHz}$ to $3 \mathrm{GHz}$ indicating that the proposed power divider can split an incoming signal into two parts successfully. The measured phase difference of the developed device, $\Delta \phi$ between $\left|S_{21}\right|$ and $\left|S_{31}\right|$ is $1.1^{\circ}$ with tolerance $\pm 0.7^{\circ}$ over the operating bandwidth as shown in Fig. 8 (b). The return loss, $\left|S_{11}\right|$ at input port of the designed power divider, is better than $-15 \mathrm{~dB}$ across the frequency

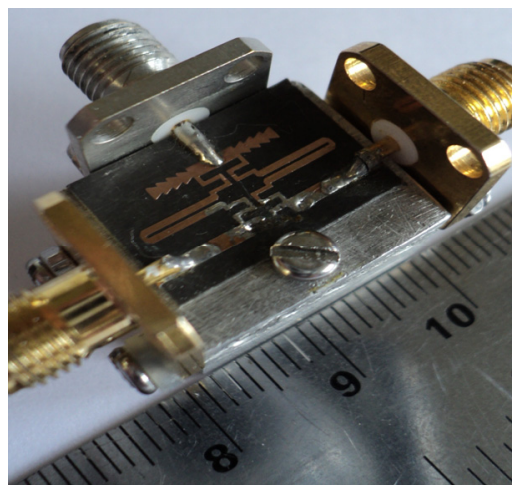

Fig. 6. Photograph circuit of the proposed.

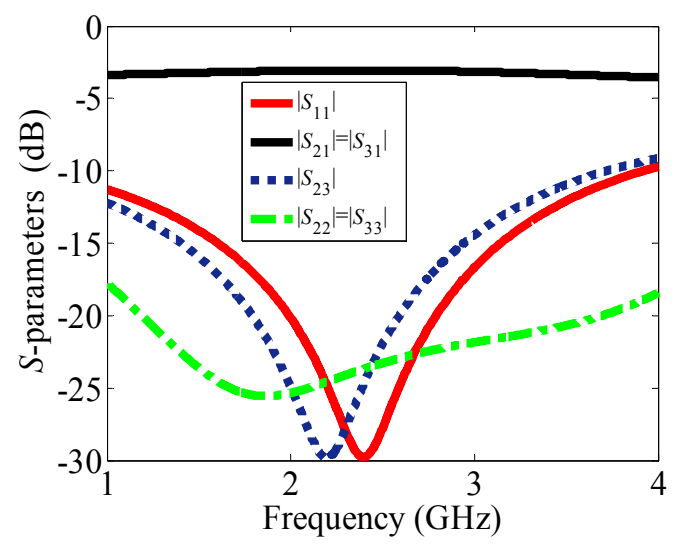

Fig. 7. $S$-parameters for simulation results.

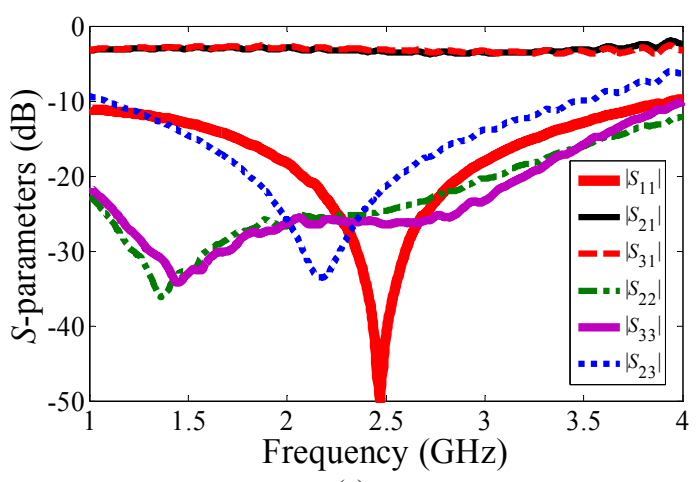

(a)

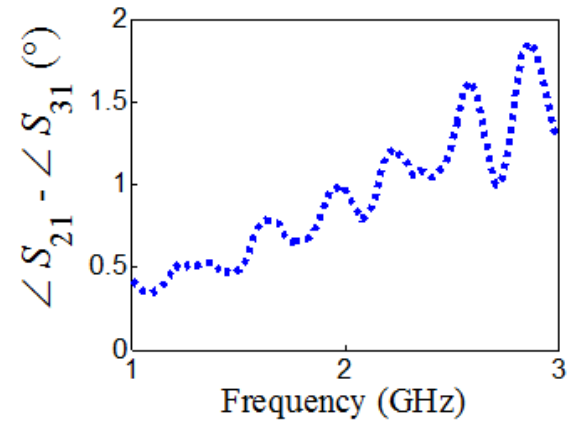

(b)

Fig. 8. $S$-parameters for measurement results. 


\begin{tabular}{|c|c|c|c|c|c|c|}
\hline Ref. & Center Freq (GHz) & FBW (\%) & $S_{11}(\mathrm{~dB})$ & $S_{23}(\mathrm{~dB})$ & Width $\times$ Length $\left(\mathrm{mm}^{2}\right)$ & Area $\left(\mathrm{mm}^{2}\right)$ \\
\hline [14] & $2-5$ & 69 & $<-10$ & $<-13$ & $0.65 \lambda_{g} \times 0.65 \lambda_{g}$ & $0.420 \lambda_{g}{ }^{2}$ \\
\hline [15] & 2.0 & 100 & $<-10$ & $<-10$ & $0.84 \lambda_{g} \times 0.48 \lambda_{g}$ & $0.400 \lambda_{g}{ }^{2}$ \\
\hline [18] & 6.85 & - & $<-10$ & $<-10$ & $0.75 \lambda_{g} \times 0.54 \lambda_{g}$ & $0.410 \lambda_{g}{ }^{2}$ \\
\hline [21] & 4.0 & 112 & $<-10$ & $<-20$ & $0.77 \lambda_{g} \times 0.75 \lambda_{g}$ & $0.580 \lambda_{g}{ }^{2}$ \\
\hline [22] & 2.4 & - & $<-10$ & $<-10$ & $0.43 \lambda_{g} \times 0.36 \lambda_{g}$ & $0.155 \lambda_{g}^{2}$ \\
\hline [24] & 2.5 & 80 & $<-9$ & $<-10$ & $0.44 \lambda_{g} \times 0.19 \lambda_{g}$ & $0.084 \lambda_{g}{ }^{2}$ \\
\hline [25] & 1.4 & 9.5 & $<-10$ & $<-16$ & $0.13 \lambda_{g} \times 0.19 \lambda_{g}$ & $0.025 \lambda_{g}^{2}$ \\
\hline [26] & 6.85 & - & $<-10$ & $<-13.56$ & $0.73 \lambda_{g} \times 0.50 \lambda_{g}$ & $0.370 \lambda_{g}{ }^{2}$ \\
\hline$[27]$ & 6.65 & - & $<-10$ & - & $0.80 \lambda_{g} \times 0.50 \lambda_{g}$ & $0.400 \lambda_{g}^{2}$ \\
\hline \multirow[t]{2}{*}{ This work } & \multirow[t]{2}{*}{2.4} & 116 & $<-10$ & \multirow[t]{2}{*}{$<-13$} & \multirow[t]{2}{*}{$0.17 \lambda_{g} \times 0.10 \lambda_{g}$} & \multirow[t]{2}{*}{$0.017 \lambda_{g}^{2}$} \\
\hline & & 69 & $<-15$ & & & \\
\hline
\end{tabular}

Tab. 2. Comparison with previous work.

interval from $1.65 \mathrm{GHz}$ to $3.3 \mathrm{GHz}$. This is equivalent to $69 \%$ fractional bandwidth and the isolation, $\left|S_{23}\right|$ between two output ports is better than $-13 \mathrm{~dB}$ from $1.5 \mathrm{GHz}$ to $3.1 \mathrm{GHz}$. It is obvious from Tab. 2 that the results achieved by this study are superior compared to the previous studies.

\section{Conclusion}

A compact Wilkinson power divider has been successfully designed and fabricated using four-series delta stubs with a stepped-impedance transmission line (FSITL) on each branch in order to obtain a compact size and a wider bandwidth. The modified power divider achieves a significant size reduction of $84 \%$ compared to a conventional power divider at $2.4 \mathrm{GHz}$. The measured results of the modified power divider showed a $116 \%$ fractional bandwidth. It also achieved good impedance matching, equal power splitting, and high isolation performance over the range shown by simulation and measurement results.

\section{Acknowledgments}

This study was supported by the Research University Grant (GUP) from Universiti Teknologi Malaysia under project number Q.J130000.2523.15H30 and the Ministry of Higher Education of Malaysia (MOHE).

\section{References}

[1] POZAR, D. M. Microwave Engineering. 4th ed. United States of America, 2011. ISBN: 978-1-118-29813-8

[2] WANG, J., NI, J., GUO, Y. X., et al. Miniaturized microstrip Wilkinson power divider with harmonic suppression. IEEE Microwave and Wireless Components Letters, 2009, vol. 19, no. 7, p. 440-442. DOI: 10.1109/LMWC.2009.2022124

[3] YANG, J., GU, C., WU, W. Design of novel compact coupled microstrip power divider with harmonic suppression. IEEE Microwave and Wireless Components Letters, 2008, vol. 18, no. 9 , p. 572-574. DOI: 10.1109/LMWC.2008.2002444

[4] TSENG, C. H., WU, C. H. Compact planar Wilkinson power divider using pi-equivalent shunt-stub-based artificial transmission lines. Electronics Letters, 2010, vol. 46, no. 19, p. 1327-1328. DOI: $10.1049 / \mathrm{el} .2010 .2194$

[5] TANG, C. W., CHEN, M. G. Synthesizing microstrip branch-line couplers with predetermined compact size and bandwidth. IEEE Transactions on Microwave Theory and Techniques, 2007, vol. 55, no. 9, p. 1926-1934. DOI: 10.1109/TMTT.2007.904331

[6] TANG, C. W., CHEN, M. G. Synthesizing microstrip branch-line couplers with predetermined compact size and bandwidth. IEEE Transactions on Microwave Theory and Techniques, 2007, vol. 55, no. 9, p. 1926-1934. DOI: 10.1109/TMTT.2007.904331

[7] SEDIGHY, S. H., KHALAJ-AMIRHOSSEINI, M. Compact Wilkinson power divider using stepped impedance transmission lines. Journal of Electromagnetic Waves and Applications, 2011, vol. 25, no. 13, p. 1773-1782. DOI: $10.1163 / 156939311797453980$

[8] DENG, P. H., GUO, J. H., KUO, W. C. New Wilkinson power dividers based on compact stepped-impedance transmission lines and shunt open stubs. Progress In Electromagnetics Research, 2012, vol. 123, p. 407-426. DOI: 10.2528/PIER11111612

[9] CHANG, C. L., TSENG, C. H. Compact Wilkinson power divider using two-section asymmetrical T-structures. Electronics Letters, 2013, vol. 49, no. 8, p. 546-547. DOI: 10.1049/el.2013.0366

[10] MESCHANOV, V. P., RASUKOVA, I. A., TUPIKIN, V. D. Stepped transformers on TEM-transmission lines. IEEE Transactions on Microwave Theory and Techniques, 1996, vol. 44, no. 6, p. 793-798. DOI: 10.1109/22.506436

[11] LIM, C., SETTALURI, R. K., TRIPATHI, V. K., et al. Compact folded-line RF power dividers. In SPIE Proceedings Series. Society of Photo-Optical Instrumentation Engineers, 2001, p. 725 to 730 .

[12] SETTALURI, R. K., WEISSHAAR, A., LIM, C., et al. Design of compact multilevel folded-line RF couplers. IEEE Transactions on Microwave Theory and Techniques, 1990, vol. 47, no. 12, p. 2331 to 2339. DOI: $10.1109 / 22.808979$

[13] SONG, K., XUE, Q. Novel ultra-wideband (UWB) multilayer slotline power divider with bandpass response. IEEE Microwave and Wireless Components Letters, 2010, vol. 20, no. 1, p. 13-15. DOI: 10.1109/LMWC.2009.2035951

[14] AHMED, U. T., ABBOSH, A. M. Design of wideband single-layer in-phase power divider using microstrip to slotline coupled structure. Microwave and Optical Technology Letters, 2015, vol. 57, no. 4, p. 789-791. DOI: 10.1002/mop.28959

[15] AHMED, U. T., ABBOSH, A. M. Modified Wilkinson power divider using coupled microstrip lines and shunt open-ended stubs. Electronics Letters, 2015, vol. 51, no. 11, p. 838-839. DOI: $10.1049 / \mathrm{el} .2015 .0595$

[16] DE LIMA COIMBRA, M. A new kind of radial stub and some applications. In IEEE 14th European Microwave Conference. 
Liege (Belgium), 1984. p. 516-521. DOI: 10.1109/EUMA.1984.333364

[17] DE LIMA COIMBRA, M. The generalized delta stubs. In International Microwave Symposium Digest. 1987, p. 1071-1075.

[18] ZHOU, B., WANG, H., SHENG, W. X. A modified UWB Wilkinson power divider using delta stub. Progress In Electromagnetics Research Letters, 2010, vol. 19, p. 49-55. DOI: 10.2528/PIERL1010180

[19] SHI, J., XU, K. Compact differential power divider with enhanced bandwidth and in-phase or out-of-phase output ports. Electronics Letters, 2014, vol. 50, no. 17, p. 1209-1211. DOI: 10.1049/el.2014.1300

[20] ABBOSH, A. M. Multilayer inphase power divider for UWB applications. Microwave and Optical Technology Letters, 2008, vol. 50, no. 5, p. 1402-1405. DOI: 10.1002/mop.23379

[21] KAO, J. C., TSAI, Z. M., LIN, K. Y., et al. A modified Wilkinson power divider with isolation bandwidth improvement. IEEE Transactions on Microwave Theory and Techniques, 2012, vol. 60, no. 9, p. 2768-2780. DOI: 10.1109/TMTT.2012.2206402

[22] LIN, C. M., SU, H. H., CHIU, J. C., et al. Wilkinson power divider using microstrip EBG cells for the suppression of harmonics. IEEE Microwave and Wireless Components Letters, 2007, vol. 17, no. 10, p. 700-702. DOI:10.1109/LMWC.2007.905595

[23] AHN, H. R., KIM, B., NAM, S. Compact UHF 3 dB MCCT power dividers. IEEE Microwave and Wireless Components Letters, 2014, vol. 24 , no. 7, p. 445-447. DOI: 10.1109/LMWC.2014.2316213

[24] KIM, I. S., LEE, C. H., LEE, D., et al. A smaller step impedance line Wilkinson power divider with an improved better stopband. Microwave and Optical Technology Letters, 2016, vol. 58, no. 7, p. 1607-1610. DOI: $10.1002 /$ mop.29871

[25] ZHAO, X. L., GAO, L., ZHANG, X. Y., et al. Novel filtering power divider with wide stopband using discriminating coupling. IEEE Microwave and Wireless Components Letters, 2016, vol. 26, no. 8, p. 580-582. DOI: 10.1109/LMWC.2016.2585551

[26] OSMAN, S. A. M., EL-TAGER, A. M. E., ABDELGHANY, F. I., et al. Two-way modified Wilkinson power divider for UWB applications using two sections of unequal electrical lengths. Progress In Electromagnetics Research C. 2016, vol. 68, p. 221-233. DOI: 10.2528/PIERC16072107

[27] DARDEER, O., ABOUELNAGA, T., MOHRA, A., et al. Compact UWB power divider, analysis and design. Journal of Electromagnetic Analysis and Applications, 2017, vol. 9, no. 2, 13 p. DOI: $10.4236 /$ jemaa.2017.92002

[28] VERMA, A. K., CHAUDHARI, N. P., KUMAR, A. Improved performance step impedance lowpass filter. AEU-International Journal of Electronics and Communications, 2013, vol. 67, no. 9, p. 761-770. DOI: $10.1016 /$ j.aeue.2013.03.003

\section{About the Authors ....}

Nadera NAJIB was born in 1990. She received her Bachelor degree in Computer Engineering from Al-Hodeidah University, Yemen, in 2009 and Master degree in Electronics and Telecommunications from Universiti Teknologi Malaysia, Malaysia in 2014. She has recently started working towards her $\mathrm{PhD}$ in the field of Microwave Engineering Her research interests include microwave passive devices.

Kok Yeow YOU was born in 1977. He obtained his B.Sc. Physics (Honours) degree in Universiti Kebangsaan Malaysia (UKM) in 2001. He pursued his M.Sc. in Microwave at the Faculty of Science in 2003 and his Ph.D. in Wave Propagation at the Institute for Mathematical Research in 2006 in Universiti Putra Malaysia (UPM), Malaysia. Recently, he is a senior lecturer at Communication Engineering Department, Faculty of Electrical Engineering, Universiti Teknologi Malaysia (UTM), Malaysia. His main personnel research interest is in the theory, simulation, and instrumentation of electromagnetic wave propagation at microwave frequencies focusing on the development of microwave passive devices and sensors for agricultural applications.

Chia Yew LEE was born in 1988. He received the Bachelor's degree in Electrical Engineering (computer) from Universiti Teknologi Malaysia (UTM), Skudai, Malaysia, in 2012. He pursued his Ph.D. in Microwave Medical Instrument at the Faculty of Biosciences \& Medical Engineering in 2017 in UTM. Currently, he is a technologist in Intel company in Malaysia.

Nor Hisham KHAMIS is an Associate Professor in the Communication Engineering Department (CED), Faculty of Electrical Engineering, Universiti Teknologi Malaysia, Skudai, Johor, Malaysia. He received his B.Sc.E.E. from the University of Evansville, Indiana, USA in 1988, M.E.Sc.E.E. from the University of New South Wales, Australia in 1992, and PhD from UTM in 2005. He joined UTM in 1989 and currently is the Head of Radar Laboratory. He is also the subject coordinator for radar courses at the faculty. His research interest includes antenna design, especially microstrip antenna, planar microwave components, wireless transmission, and propagation studies; and now is the Head of Sonar Technology and Marine Instrumentation (STAR) Research Group. He is a member of Eta Kappa Nu (Electrical Engineering Honor Society, USA).

Mohamad Ngasri DIMON was born in 1961. He obtained his B.Sc. degree in Electrical Engineering (Telecommunication Engineering Option) from University of Southwestern Louisiana, Lafayette, Louisiana, USA in 1987. He completed his Master of Electrical Engineering in Acoustics Engineering in 1992 and PhD in Acoustics Engineering from UTM in 2002. Recently, he is an Assoc. Prof. at Communication Engineering Department, Faculty of Electrical Engineering, Universiti Teknologi Malaysia (UTM), Malaysia. His main research interest is in acoustics engineering with emphasis on room acoustics modelling, building acoustics local standard adaptation and development of electromagnetic wave application at microwave frequencies. 


\section{Appendix}

\begin{tabular}{|c|c|c|c|}
\hline$n$ & $a_{n}$ & $b_{n}$ & $c_{n}$ \\
\hline 1 & $-67.29325075530255(\mathrm{GHz} / 4)$ & $63.10265220824374\left(\mathrm{GHz} / \mathrm{o}^{4}\right)$ & $-313.3932265329918\left(\mathrm{GHz} /{ }^{4}\right)$ \\
\hline 2 & $8614.177776198560\left(\mathrm{GHz} / \mathrm{o}^{3}\right)$ & $-625.4295580827476\left(\mathrm{GHz} / \mathrm{o}^{3}\right)$ & $41403.63899495215\left(\mathrm{GHz} / \mathrm{o}^{3}\right)$ \\
\hline 3 & $-374486.1161421590\left(\mathrm{GHz} / \mathrm{o}^{2}\right)$ & $-352222.1266641890\left(\mathrm{GHz} / \mathrm{o}^{2}\right)$ & $-1773156.863270692\left(\mathrm{GHz} / \mathrm{o}^{2}\right)$ \\
\hline 4 & $6594974.628843251(\mathrm{GHz} / \mathrm{o})$ & $14844947.94203831(\mathrm{GHz} / \mathrm{o})$ & $30995848.35864644(\mathrm{GHz} / \mathrm{o})$ \\
\hline 5 & $-49725156.68841339(\mathrm{GHz})$ & $59093631.40386294(\mathrm{GHz})$ & $-255185051.0130994(\mathrm{GHz})$ \\
\hline
\end{tabular}

Tab. A. Values for equations (2) - (5). 